\title{
ENTRE MINÚCIAS POÉTICAS: A TRADUÇÃO DA PONTUAÇÃO EM MILTON DE WILLIAM BLAKE ${ }^{1}$
}

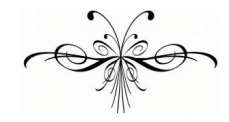

JULIANA STEIL

Resumo: $O$ presente artigo discute a tradução da pontuação usada por Blake em seus livros proféticos, concentrando-se em Milton. Para isso, examina especialmente duas traduções desse poema em língua portuguesa: a realizada por Manuel Portela (Blake, 2009) e uma tradução de estudo. Argumenta-se que a pontuação não convencional de Blake reflete inclinações filosóficas de sua obra profética, de forma que a opção de normalizar o referido recurso no texto traduzido pode levar a um enfraquecimento da estrutura poética da obra em questão.

Palavras-chave: William Blake; Milton; pontuação; tradução literária.

\begin{abstract}
This article discusses the translation of the punctuation used by Blake in his prophetic books, focusing on Milton. In order to do so two particular translations into Portuguese of this poem are analysed: the translation by Manuel Portela (Blake, 2009) and a translation of my pen made for study purposes. It is argued that Blake's unconventional punctuation reflects philosophical perspectives of his prophetic work, so that the choice for a standardization of that feature in the translated text may weaken the poetic texture of such work.
\end{abstract}

Keywords: William Blake; Milton; punctuation; literary translation.

\section{o comentar seu processo de criação artística, o poeta-pintor William Blake (1757-1827) ressaltava, em suas anotações, a interdependência entre a ideia e seu meio de expressão:}

Ouvi muita Gente dizer Mostre as Ideias. Não importa em quais Palavras colocá-las \& outros dizerem Mostre o Protótipo a Execução não é problema. Essa Gente entende o Suficiente de Artifício mas Nada De Arte. As Ideias não podem ser Mostradas a não ser em suas minuciosamente Apropriadas Palavras e um Protótipo não pode ser feito sem sua minuciosamente Apropriada Execução ${ }^{2}$ (Erdman, 1988, p. 576).

\footnotetext{
${ }^{1} \mathrm{O}$ tema apresentado nesse artigo foi anteriormente discutido em: STEIL, Juliana. Tradução comentada de Milton de William Blake. 2011. Tese (Doutorado) - Curso de Pós-graduação em Estudos da Tradução, UFSC, Florianópolis, 2011.

2 "I have heard many People say Give me the Ideas. It is no matter what Words you put them into \& others say Give me the Design it is no matter for the Execution. These People know Enough of Artifice but Nothing Of Art. Ideas cannot be Given but in their minutely Appropriate
} 
Esse princípio parece de fato aplicar-se à prática artística do autor na utilização de ao menos uma série de recursos estilísticos presentes em sua obra pictórica e/ou poética. Detenhamo-nos ao texto verbal de seus poemas e vejamos, por exemplo, o caso da pontuação usada em seus livros proféticos: tal pontuação, utilizada de modo peculiar, reflete, na forma de uma redundância motivada, ideias do sistema filosófico apresentado ao longo desses livros. Levar em consideração elementos como a pontuação parece fundamental para a tradução do texto poético de Blake, se o objetivo for uma tradução que se assemelhe ao que Henri Meschonnic identificaria como uma tradução do ritmo: "fazer na língua de chegada, com seus meios próprios, o que o texto fez na sua língua" (Meschonnic, 2010b, p. 16), sendo o texto entendido como um contínuo em que "o sentido está ligado à forma do sentido" (Meschonnic, 2010, p. 31). Com uma análise de traduções, em língua portuguesa, de Milton a Poem in 2 Books (Blake, 2009, e uma proposta de tradução concluída em 2011, para fins de pesquisa), um dos três livros considerados por muitos o ápice do estilo poético de Blake, tentaremos demonstrar a importância do tratamento da pontuação do autor na retextualização de seu discurso profético. A análise inclui, ainda, alguns pontos de comparação com a única tradução de Jerusalem (Blake, 2010) existente em português até o momento.

Antes de avaliarmos de perto a tradução do recurso da pontuação do texto de Blake, será valioso lembrar que o autor nutria uma tendência antinomiana de ver a organização social e o relacionamento com o divino. Esta tendência pode ser encontrada na tradição dissidente inglesa e tem raízes no ambiente das seitas e igrejas radicais do século XVII. Segundo Mee (1994, p. 48), o "antinomianismo de Blake era parte de um revival mais amplo [da cultura dissidente do século anterior] que acontecia a seu redor na cultura popular de Londres".

O antinomianismo, ou antinomismo, pode ser identificado como a opinião radical que nega a ideia de que as leis morais mantêm a união do cristão com Deus. Pode-se dizer, com Mee (1994), que essa noção de "graça livre" - a salvação adquirida independentemente da obediência a qualquer código de lei ética ou moral - tem origem na leitura de passagens como I João 3:9: "Todo aquele que nasceu de Deus não comete pecado, / porque sua semente permanece nele; / ele não pode pecar / porque nasceu de Deus" (Bíblia de Jerusalém). Diferentes reações antinomianas podem ser relacionadas a passagens como esta; algumas se mantêm no plano teórico apenas, enquanto outras encontram a convicção prática de um estado de salvação já alcançado. Para Mee, The Marriage of Heaven and Hell aproxima-se desse tipo de extremismo antinomiano. De fato, esta é a impressão suscitada por excertos como:

Porque tudo o que vive é Sagrado.

(Blake, 2001, p. 59)

Digo-te: nenhuma virtude pode existir sem a quebra desses dez mandamentos. Jesus era todo virtude, e agia por impulso, não por regras.

(Blake, 2001, p. 51)

Words nor Can a Design be made without its minutely Appropriate Execution" (Public Address). 
Das características da tendência antinomiana identificáveis na obra de Blake, uma das mais importantes é a crença na superioridade do espírito sobre a presença da lei, "o que envolve uma antipatia anticlerical, aos aspectos cerimoniais e institucionais da religião", uma antipatia que se estende a qualquer autoridade e a leis em geral (Mee, 1994: 44). Nos níveis discursivos superficiais de suas profecias, a transgressão das normas da escrita padrão pode ser lida como uma das manifestações do antinomianismo do autor. Em Milton, por exemplo, o próprio fluxo narrativo representa uma dessas transgressões; para descrevê-lo, Fox (1976, p. 17) sugere o princípio de simultaneidade:

A ideia de simultaneidade através da identificação de figuras e ações é um elemento central em Milton; na verdade, é o elemento pelo qual a sua sobreposição de perspectivas é alcançada: as várias percepções e reações do poema parecem lineares, parecem influenciar e levar umas às outras progressivamente, até percebermos que todas elas, com exceção daquelas que são explicitamente prefaciais, ocorrem simultaneamente e que, assim, não podem ser lineares $^{4}$.

Essick \& Viscomi (1993) concordam com o argumento sobre as "estruturas sobrepostas" da narrativa não linear de Milton. Eles defendem a hipótese de que

uma das intenções de Blake ao escrever Milton era criar essas dificuldades [de leitura] (...) e confundir as pressuposições básicas sobre o eu e o outro, sobre tempo e espaço, nos quais normalmente nos apoiamos ao ler textos que parecem seguir as mesmas regras do nosso mundo cotidiano ${ }^{5}$ (Essick \& Viscomi, 1993, p. 10).

Produzir uma leitura próxima aos padrões tradicionais "frustraria suas intenções ao acomodar o não convencional a modos de discurso convencionais" (Essick \& Viscomi, 1993, p. 12). No entanto, Blake não negligencia totalmente os padrões convencionais: ele "não prescinde completamente - e nem poderia, se quisesse um mínimo de público - da gramática e da sintaxe de sua língua herdada, mas vai bastante longe em forçar o inglês para além de seus limites"6 (Essick \& Viscomi, 1993, p. 12). Certamente, um desses limites que o autor força é a pontuação.

A pontuação de Blake, assim como a sua ortografia, é sempre matéria controversa entre os editores de sua obra. Além de não seguir as normas do inglês escrito, há o problema da caligrafia dos originais, que muitas vezes dificulta sua transcrição. À parte a dificuldade da transcrição textual, o uso dos sinais gráficos ao longo dos poemas proféticos é um item difícil de descrever sistema-

\footnotetext{
3 “(...) an anticlerical antipathy to the cerimonial and institutional aspects of religion".

4 "The suggestion of simultaneity through identification of figures and actions is a major device of Milton, the device, in fact, by which its layering of perspectives is enforced: the various perceptions and reactions of the poem seem linear, seem to influence and elict each other progressively, until we recognize that all of them except those that are explicitly prefatory occur simultaneously and therefore cannot be linear".

5 "Let us entertain the notion that one of Blake's purposes in writing Milton was to create these difficulties (...) and disconcert the very presuppositions about self and other, space and time, we normaly rely on when reading texts that appear to follow the same rules as our everyday world".

6 "Blake does not - indeed, could not, if he wanted any audience at all - completely dispense with the Grammar and syntax of his inherited language, but he goes a long way in forcing English to its outer boundaries".
} 
ticamente. Alguns traços podem ser verificados desde o início: Blake não usa reticências nem aspas; raramente usa parênteses. O emprego do ponto final, dos dois-pontos, da vírgula, do ponto-e-vírgula, do ponto de exclamação e do ponto de interrogação, no entanto, não é estável.

O ponto final pode ocorrer na frase em locais inesperados ${ }^{7}$ :

Hand is become a rock! Sinai \& Horeb, is Hyle \& Coban: ${ }^{8}$

(M, C: 20)

A mão tornou-se rochedo! Sinai \& Horeb são Hyle \& Coban

(Portela - Blake, 2009, p. 103)

Hand is become a rock; Sinai \& Horeb. is Hyle \& Coban:

( $M, \mathrm{~B}: 17)$

Hand se torna em pedra; Sinai \& Horebe. é Hyle \& Coban:

(Steil)

The Souls descending to the Body, wail on the right hand Of Los; \& those deliverd from the Body, on the left ${ }^{9}$ (M, C: 27)

As Almas que descem ao Corpo, gemem à mão direita

De Los; \& as que se libertam do Corpo, à esquerda

(Portela - Blake, 2009, p. 141)

The Souls descending to the Body. wail on the right hand Of Los; \& those deliverd from the Body. on the left hand $(M, \mathrm{~B}: 26)$

As Almas que descem ao Corpo. elas choram à mão direita De Los; \& aquelas que são libertas do Corpo. à mão esquerda (Steil)

Bowlahoola is namd Law, by mortals, Tharmas founded it: ${ }^{10}$

(M, C: 25)

Bowlahoola é chamada Lei pelos mortais, Tharmas foi seu fundador:

(Portela-Blake, 2009, p. 131)

Bowlahoola is namd Law. by mortals, Tharmas founded it:

(M, B: 23)

Bowlahoola é chamada Lei. por mortais, Tharmas a criou:

(Steil)

There is in Eden a sweet River. of milk \& liquid pearl,

(M, B: 19)

Há no Éden um doce Rio. de leite \& líquida pérola, (Steil)

\footnotetext{
${ }^{7}$ No padrão de referência adotado para as transcrições dos originais, a letra em itálico se refere à inicial do livro ("M" para "Milton"; " $J$ " para "Jerusalem"); a letra subsequente se refere ao exemplar do original e o número à página da transcrição, seguindo a catalogação do William Blake Archive. As referências "Steil” indicam os versos traduzidos pela autora do artigo.

${ }^{8}$ Este é o verso conforme transcrito na edição da Antígona. Na transcrição do exemplar $\mathrm{C}$ de Milton disponível no Blake Archive lê-se:

Hand is become a rock! Sinai \& Horeb. is Hyle \& Coban:

${ }^{9}$ The Souls descending to the Body. wail on the right hand Of Los; \& those deliverd from the Body. on the left hand (Eaves, Essick \& Viscomi, 2011)

${ }^{10}$ Bowlahoola is namd Law. by mortals, Tharmas founded it: (Eaves, Essick \& Viscomi, 2011)
} 
(Which is the Divine Body of the Lord Jesus. blessed for ever). ${ }^{11}$ $(J, \mathrm{E}: 5)$

(Que é o Corpo Divino do Senhor Jesus. abençoado para sempre).

(Alencastre - Blake, 2010, p. 50)

Os dois-pontos podem estar no lugar onde caberia, segundo a pontuação tradicional, o ponto final ou a vírgula:

This Voltaire \& Rousseau: this Hume \& Gibbon \& Bolingbroke (M, C: 45)

Este Voltaire \& Rousseau: este Hume \& Gibbon \& Bolingbroke (Portela - Blake, 2009, p. 213)

This Voltaire \& Rousseau: this Hume \& Gibbon \& Bolingbroke (M, B: 42)

Esse Voltaire \& Rousseau: esse Hume \& Gibbon \& Bolingbroke (Steil)

Mine is the fault! I should have remember'd that pity divides the soul And man, unmans: follow with me my Plow, this mournful Day ${ }^{12}$ $(M, \mathrm{C}: 7)$

A culpa é minha! Deveria ter-me lembrado que a piedade divide a alma E desumaniza o homem: segui-me com o Arado, este dia funéreo (Portela - Blake, 2009, p. 57)

Mine is the fault! I should have remember'd that pity divides the soul And, man, unmans: follow with me my Plow, this mournful Day (M, B: 6)

A culpa é Minha! Deveria lembrar que a compaixão divide a alma E, o homem, desominiza: vinde comigo meu Arado, esse dia (Steil)

The wine of the Spirit \& the vineyards of the Holy-One.

Here: turn into poisonous stupor \& deadly intoxication:

$(J, \mathrm{E}: 43)$

O vinho do Espírito \& as vinhas do Santíssimo.

Aqui: transformam-se em estupor venenoso \& intoxicação mortífera:

(Alencastre - Blake, 2010, p. 131)

Quando uma fala é anunciada, não são usados dois-pontos, mas ponto final, vírgula, ou nenhum sinal gráfico:

And Milton said. "I go to Eternal Death!” Eternity shudder' $d^{13}$

(M, C: 14)

E Milton disse, "Entrego-me à Morte Eterna!" A Eternidade estremeceu

(Portela - Blake, 2009, p. 83)

And Milton said. I go to Eternal Death; Eternity shudder'd

(M, B: 12)

E Milton disse. Eu vou para a Morte Eterna; a Eternidade tremeu (Steil)

\footnotetext{
${ }^{11}$ Alencastre seguiu a edição de Erdman (1988). Jerusalem, E (Eaves, Essick \& Viscomi, 2011): Which is the Divine Body of the Lord Jesus. blessed for ever).

${ }^{12}$ Mine is the fault! I should have remember'd that pity divides the soul And, man, unmans: follow with me my Plow, this mournful Day (Eaves, Essick \& Viscomi, 2011)

${ }^{13}$ And Milton said. I go to Eternal Death; Eternity shudder'd (Eaves, Essick \& Viscomi, 2011)
} 


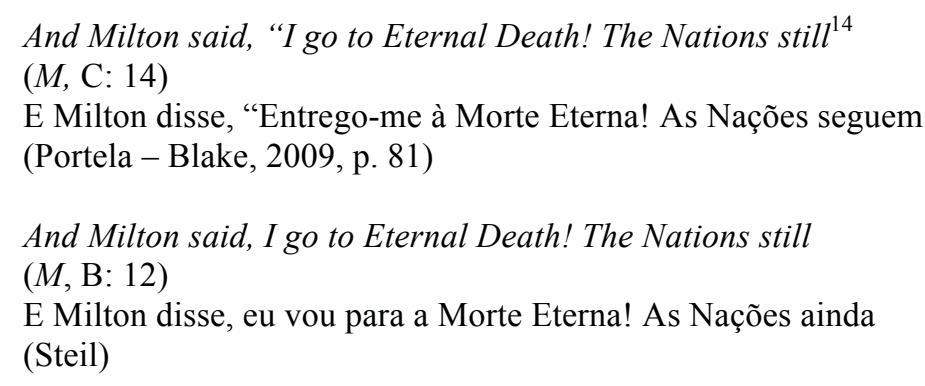

And Albion spoke from his secret seat and Said (J, E: 28)

E Albion falou de seu lugar secreto e disse

(Alencastre - Blake, 2010, p. 97)

É comum a repetição de dois-pontos nos versos:

Osiris: Isis: Orus: in Egypt: dark their Tabernacles on Nile (M, C: 40)

Osíris: Íris: Horus: no Egito: negros os seus Tabernáculos no Nilo

(Portela - Blake, 2009, p.197)

Osiris: Isis: Orus: in Egypt: dark their Tabernacles on Nile (M, B: 37)

Osíris: Ísis: Hórus no Egito: sombrias as suas Tendas no Nilo (Steil)

Now Leutha ceas'd: tears flow'd: but the Divine Pity, supported her. ${ }^{15}$ (M, C: 13)

Eis que Leutha cessou: as lágrimas correram: mas a Piedade Divina susteve-a.

(Portela - Blakeb, 2009, p. 77)

Now Leutha ceas'd: tears flow'd: but the Divine Pity supported her. $(M, \mathrm{~B}: 11)$

Leutha cessou: lágrimas rolaram: mas a Divina Misericórdia a conforta. (Steil)

Said thus. What seems to Be: Is: To those to whom ${ }^{16}$ $(J, \mathrm{E}: 36)$

Disseram assim. O que parece Ser: É: Para aqueles a quem (Alencastre - Blake, 2010, p. 117)

O ponto-e-vírgula aparece em lugar do ponto de interrogação, da vírgula e do dois-pontos:

\footnotetext{
${ }^{14}$ And Milton said, I go to Eternal Death! The Nations still (Eaves, Essick \& Viscomi, 2011)

${ }^{15}$ Now Leutha ceas'd: tears flow'd: but the Divine Pity supported her. (Eaves, Essick \& Viscomi, 2011)

${ }^{16}$ Said thus, What seems to Be: Is; To those to whom (Eaves, Essick \& Viscomi, 2011)
} 
The Virgin answerd. "Knowest thou of Milton who descended Driven from Eternity? him I seek! terrified at my Act $^{17}$

$(M, \mathrm{C}: 40)$

A Virgem respondeu: "Sabes onde está Milton que desceu

(Portela - Blake, 2009, p. 195)

The Virgin answerd. Knowest thou of Milton who descended Driven from Eternity; him I seek! terrified at my Act

$(M, \mathrm{~B}: 37)$

A Virgem respondeu. Acaso sabes de Milton aquele que desceu

(Steil)

Exploring the Three States of Ulro; Creation; Redemption. \& Judgment $(J, \mathrm{E}: 36)$

Explorando os Três Estados de Ulro; Criação, Redenção. \& Julgamento (Alencastre - Blake, 2010, p. 116)

O ponto de interrogação não costuma aparecer em locais aleatórios, mas pode constar ou ser omitido nos lugares recomendados pelas regras convencionais:

When shall Jerusalem return \& overspread all over the Nations

(M, C: 5)

Quando voltará Jerusalém \& cobrirá todas as Nações?

(Portela - Blakeb, 2009, p. 49)

When shall Jerusalem return \& overspread all the Nations

(M, B: 4)

Quando regressará Jerusalém \& a se estender por todas as Nações

(Steil)

Why have thou elevate inward: $O$ dweller of outward chambers ${ }^{18}$ ( $J, \mathrm{E}: 34)$

Por que elevaste para dentro: Ó habitante das câmaras exteriores

(Alencastre - Blake, 2010, p. 111)

Como podemos notar, não parece ser objetivo do poeta usar a pontuação para a organização lógica do texto. Então, esse uso não é sistematizado: uma vírgula no texto do poeta pode indicar uma pausa da mesma maneira que um ponto, dois-pontos, ou ponto-e-vírgula, indiferentemente, ignorando a função lógica de cada um desses sinais na pontuação convencional. A pontuação idiossincrática de Blake despreza as normas da escrita de seu tempo, contesta a organização racional do pensamento a partir da adequação a regras estabelecidas, harmoniza-se com a inclinação antinomiana de seu sistema filosófico.

Os excertos das traduções apresentados acima permitem constatar que o efeito de desestabilização dos padrões de pontuação gráfica que é observado em Milton se perde à medida que a tradução procura adequar o texto a esses mesmos padrões. Isso acontece na tradução de Manuel Portela, que explica a sua estratégia da seguinte maneira:

\footnotetext{
${ }^{17}$ The Virgin answerd. Knowest thou of Milton who descended (Eaves, Essick \& Viscomi, 2011) Driven from Eternity; him I seek! terrified at my Act

${ }^{18}$ Why have thou elevate inward; $O$ dweller of outward chambers (Eaves, Essick \& Viscomi, 2011)
} 
No que diz respeito aos sinais de pontuação, o texto foi também confrontado com a edição de Geoffrey Keynes (1957). Keynes introduziu as aspas para identificar as falas das personagens e modernizou o uso de vírgulas, pontos, pontos-e-vírgulas, dois-pontos, travessões, pontos de exclamação e pontos de interrogação, tornando o texto mais legível para o leitor actual, embora por vezes de modo invasivo. Com excepção das aspas, em que segui Keynes, os restantes sinais de pontuação que alterei no texto de Erdman passaram pela observação de fac-símiles digitais das iluminuras originais e pela consideração das vantagens relativas de uma transcrição (próxima das edições de Erdman, de Essick e Viscomi, e do Arquivo William Blake) e de uma notação convencional (próxima de Keynes) (Portela in Blake, 2009, p. 21).

Nesse comentário, o tradutor explica que o texto em inglês foi estabilizado por ele a partir de várias edições do original, incluindo a fac-similar. Continua Portela:

Em geral, a pontuação que adotei no texto original aproxima-se da transcrição textual. As únicas modificações significativas dizem respeito à introdução de aspas para identificar as falas e à transformação de pontos em vírgulas quando a sintaxe assim o requeria. A dificuldade em fixar a pontuação das gravuras de William Blake deve-se a dois motivos. Por um lado, Blake não era coerente nem sistemático na pontuação e, no caso de Milton, esse facto é ainda mais notório do que nos poemas iluminados anteriores. Passos suficientemente pontuados alternam com passos escassamente pontuados, dando a ideia de que as próprias divisões de verso e os espaços da gravura funcionam não apenas como marcadores rítmicos, mas também como pontuadores sintácticos e semânticos. Além da falta de sinais, como pontos de interrogação e pontos finais, por vezes há sinais mal colocados. Por outro lado, muitas marcas impressas que resultam da gravação revelam-se ambíguas: vírgulas e pontos finais são frequentemente idênticos na impressão; e o mesmo acontece com os sinais de ponto e vírgula, de dois pontos e de exclamação, que se confundem entre si. Por isso, em certos casos, a transcrição meramente documental tem de ser rectificada de acordo com o contexto gráfico-semântico imediatamente anterior ou posterior da palavra, do verso ou da frase (Portela in Blake, 2009, pp. 2122).

De outro lado, o tradutor afirma que

Também no texto português preferi manter a pontuação próxima do original, procurando limitar a normalização da pontuação. Além das alterações já referidas no texto de partida, introduzi algumas vírgulas, pontos finais e pontos de interrogação sempre que me pareceram imprescindíveis para clarificar as relações entre os vários elementos da frase em português, como em expressões ou orações intercaladas, vocativos, interrogações e certas enumerações. No entanto, em muitos casos, a divisão de verso e a estrutura sintáctica da frase permite suprir a ausência de pontuação. Tal como fiz nas traduções anteriores, evitei uma uniformização e normalização excessiva (...) (Portela in Blake, 2009, p. 22).

O tradutor demonstra conhecer bem as características da pontuação no texto de Milton; ao mesmo tempo, não resiste a corrigir os sinais "mal colocados" e fazer as demais alterações "imprescindíveis para clarificar" a frase em português. Portela afirma que inseriu, no original e na tradução, as aspas para indicar as falas; introduziu vírgulas, pontos finais e pontos de interrogação; transformou pontos em vírgulas; mas afirma que preferiu "manter a pontuação próxima do original, procurando limitar a normalização da pontuação". 
Essa inclinação pela "normalização" do texto é compartilhada pelos próprios editores mais antigos de Blake, e por muitos editores de outros autores, antigos e recentes, como nota Meschonnic (2006, pp. 19-23). A justificativa mais comum para esse tipo de intervenção, a de facilitar a leitura, é passível de debate. Pelo menos no caso de Blake, não é difícil o leitor se habituar com a sua pontuação após algumas páginas, e não há nada verdadeiramente incompreensível nesse sentido em sua escrita que leve à necessidade de torná-lo "mais legível para o leitor actual". Mais importante que isso, o processo de normalização do texto blakiano contradiz a proposta de um texto que contesta, de várias maneiras, os padrões estabelecidos.

A título de comparação, se verificarmos a tradução existente em língua portuguesa de Jerusalem, perceberemos que o tradutor Saulo Alencastre oferece uma alternativa mais consistente para lidar com o problema da pontuação: seguiu uma única edição (Erdman, 1988) e definiu a disposição dos sinais de acordo com ela. Isso inclui transferir para a sua tradução, e para o leitor dessa, até mesmo as dúvidas anotadas pelo editor:

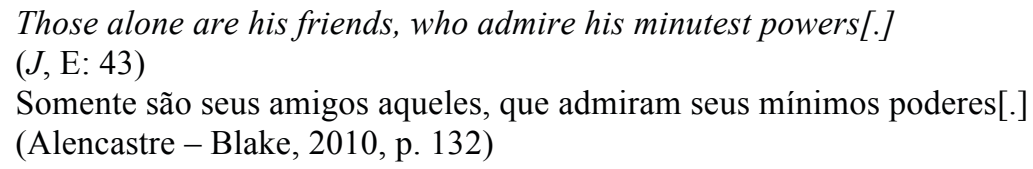

Assim, a tradução reproduz algumas inserções feitas pelo editor e, nessas ocasiões, que são em número reduzido, ela normaliza o texto, como a tradução de Portela. No restante do texto, a tradução de Alencastre segue a pontuação peculiar de Blake, segundo Erdman (1988).

Entendemos que a pontuação de Milton não é, como pode parecer, um detalhe pouco importante na configuração poética da obra. Assim, em nossa tradução do livro, preferimos acompanhar a transcrição mais transparente possível dos impressos originais e, ao transferir a pontuação idiossincrática para o texto de chegada, acreditamos haver atingido o efeito de desestabilização dos padrões da escrita sugerido no texto de Blake.

Juliana Steil julianasteil@gmail.com Doutora egressa, Universidade Federal de Santa Catarina 


\section{Referências bibliográficas}

Bíblia de Jerusalém. São Paulo: Paulus, 2002.

Blake, William. O Matrimônio do Céu e do Inferno / O Livro de Thel. Tradução de José Antônio Arantes. $4^{\mathrm{a}}$ edição. São Paulo: Iluminuras, 2001. . Jerusalém. Tradução de Saulo Alencastre. São Paulo: Hedra, 2010. - Milton. Tradução, introdução e notas de Manuel Portela. Lisboa: Antígona, 2009.

EAVES, Morris; Robert N. ESSICK \& Joseph VISCOMI (eds.). The William Blake Archive. <http://www.blakearchive.org/>. 2011.

Erdman, David V. The Complete Poetry \& Prose of William Blake. Newly revised edition. New York / London / Toronto / Sydney / Auckland: Anchor Books, 1988.

Essick, Robert N. \& Joseph VISCOMI (eds.). Milton a Poem, and the final illuminated works: Laocoön, The Ghost of Abel, and On Homers Poetry. In: BINDMAN, David (general editor). The Complete Illuminated Books of William Blake. Vol. 5. London: The Tate Gallery / The William Blake Trust, 1993.

MeE, Jon. "The After-Life of a Heresy". In: CLARK, Steve \& David Worral (ed.). Historicizing Blake. New York: St. Martin's Press, 1994.

Meschonnic, Henri. Linguagem - ritmo e vida. Extratos traduzidos por Cristiano Florentino, com revisão de Sônia Queiroz. Belo Horizonte: FALE/UFMG: 2006.

. Poética do Traduzir. Tradução de Jerusa Pires Ferreira \& Suely Fenerich. São Paulo: Perspectiva, 2010.

. "Traduzir: escrever ou desescrever". Tradução de Claudia Borges de Faveri \& Marie-Helénè Catherine Torres. In: Scientia Traductionis, $\mathrm{n}^{\circ} 7$. Florianópolis: PGET/NUPLITT, $2010 \mathrm{~b}$. 